\title{
Contributions from Taoist Stories to the Ecological-Spiritual Crisis of Contemporary Mankind
}

\author{
José Arlés Gómez Arévalo
}

\begin{abstract}
This article presents the results of work done by the research group Science- Spirituality, whose third phase is called The Concept of Natural Harmony in Regards to the Man-nature Relationship: A Dialogue between Western and Eastern Cultures. This phase is an attempt to borrow from emerging Western epistemologies together with Far East traditions, primarily the ancient Chinese Taoist tradition. Taking as a starting point the contemporary mankind crisis which has been proclaimed by philosophy, science and culture and regarding that which thinkers and scientists alike, such as Husserl and Prigogine have concluded, the limitations of modern-thinking are highlighted and a thorough revision of this thinking has been proposed. This revision must be done based on the sense of humanity and on the dialogue between sciences and other cultures. In this case: Far Eastern culture.
\end{abstract}

This research work is built upon the idea of examining our perception concerning Taoist culture, assuming that this culture is reflected in its narratives and fables and that they offer an opportunity to gain new insights and meanings regarding the world and some of the issues faced by contemporary humankind. Thus, the category crisis becomes particularly important since it is understood as a challenge or opportunity in an increasingly globalized and technology-oriented world marked by problems such as inequality, exclusion, paradoxes and the contradictions of the human being, including himself, others and furthermore a permanent critical relationship to nature from which he or she has been disconnected in a physical, spiritual and energetic way (Guenon, 2010, 34).

\section{KeYWORDS}

Eastern traditions, stories, Taoism, yin yang, crisis.
Recibido: 18 de enero de 2012 Evaluado: 24 de febrero de 2012 Aceptado: 26 de marzo de 2012 
"La imaginación es más poderosa que el conocimiento".

Einstein

"Soñé que era una mariposa. Volaba en el jardín de rama en rama. Solo tenía conciencia de mi existencia de mariposa y no

la tenía de mi personalidad de hombre.

Desperté y ahora no sé si soñaba que era una mariposa o si soy una mariposa que sueña que es hombre".

\section{Chuang Tzú}

\section{INTRODUCCIÓN}

“Tal es la ley del cielo y la tierra, tales los poderes del sabio: quietud, tranquilidad, despojo exterior, viajar ligero. El sabio reposa; porque reposa, está en paz; su paz

es serenidad. Al pacífico y sereno no lo asaltan ni dañan alegría o tristeza. Intacto, entero, unido a sí mismo y a su ser interior, es invencible".

Proverbio taoísta

Desde el Lejano Oriente se puede rastrear una riqueza insondable representada en sus relatos y narrativas ${ }^{1}$ que dan cuenta de una visión profunda del hombre, del cosmos y de la trascendencia (Gómez y Vallejo, 2007).

1 Se comprende en este trabajo investigativo, como narrativa, la cualidad estructurada de la experiencia entendida y vista como un relato; por otro, como enfoque de investigación, las pautas y formas de construir sentido, a partir de acciones temporales personales, por medio de la descripción y análisis de los datos biográficos. Es una particular reconstrucción de la experiencia, por la que, mediante un proceso reflexivo, se da significado a lo sucedido o vivido (Ricoeur 1995). A su vez, la narrativa se entiende como trama argumental, secuencia temporal, con personajes y situaciones que son elementos constitutivos de la configuración narrativa (Clandinin y Connelly, 2000). Narrativizar la vida en un autorrelato es - como dicen Bruner o Ricoeur - un medio de inventar el propio yo, de darle una identidad (narrativa). En su expresión superior (autobiografía) es también elaborar el proyecto ético de lo que ha sido y será la vida (Bolívar, 1999).
Es así como desde los relatos, fábulas y narraciones, grandes culturas como la hindú y la de China, fueron legitimando ${ }^{2}$ sus formas de construir conocimiento, de concebir el mundo y relacionarse con la naturaleza; la gran primacía en dichas tradiciones orientales, era que el pensamiento y la misma sabiduría, no se encontraban cautivos en el ámbito filosófico o científico solamente (Fischl, 2002, p. 87), sino que por el contrario, se integraban en las experiencias místico-espirituales, en las expresiones emotivas y en sus mitos colmados de enorme simbolismo (Zhuang Zi, 2007, p. 49).

En toda esta frondosidad de expresiones y de experiencias, emergen los relatos de la cultura taoísta, plasmados de manera especial en diversas fuentes, entre ellas el Tao Te $K_{i n g}{ }^{3}$, atribuido al sabio Lao Tsé y los aforismos del maestro Chuang Tzú ${ }^{4}$, famoso filósofo del siglo IV a. C. Dichos relatos tienen un trasfondo sapiencial y educativo, especialmente cuando aparece la crisis como experiencia entre el hombre y la naturaleza.

2 Muchos autores, entre ellos Becerra (2011), concuerdan en que cualquier forma de legitimación, ayuda a establecer el orden social, para institucionalizar una idea o simplemente para ejercer la facultad de nominar, supone la capacidad de producir el contexto que la hace legible y dirigir los mecanismos de recepción de el sentido. Se trata de un proceso de participación en el que la parte entrega su lógica a la contraparte, que la retoma sin notarlo: quien ejerce el poder con legitimidad, lo hace investido por la ley de la aceptación.

3 Esta obra es una de los más importantes en la filosofía y la tradición china; a su vez, es el fundamento del taoísmo, con una clara impronta en la tradición del budismo chan. Asimismo es importante recordar que en la China antigua, muchos artistas, pintores, calígrafos y hasta jardineros han usado este libro como fuente de inspiración. Su influencia se ha extendido también más allá del Lejano Oriente, ayudada por las muchas traducciones diferentes del texto a lenguas occidentales.

4 Chuang Tzu o Chuang Tse, literalmente "Maestro Zhuang", fue un famoso filósofo de la antigua China que vivió alrededor del siglo IV a. C. durante el período de los Reinos combatientes, y que corresponde a la cumbre del pensamiento filosófico chino llamado las "Cien Escuelas de Pensamiento". 
De esta manera, en plena época de "crisis"5 a todo nivel, las narrativas del Lejano Oriente, aportan aún después de muchos siglos, una sabiduría y un sentido didáctico que trasciende los límites del tiempo y del espacio (García-Noblejas, 2007, p. 103), de manera especial, en una época signada por la violencia, el egoísmo y la falta de compromiso a todo nivel, elementos claros que señalan un conflicto permanente y en donde la presencia de la misma ciencia no está ausente como afirma Lyotard (1989), en La condición postmoderna.

Este pensador francés, afirma que muchas veces se da un conflicto desde el saber de la ciencia, pues se valora el saber narrativo ${ }^{6}$ como "inferior" al discurso científico, lo que ha servido como base del imperialismo cultural occidental (Lyotard, 1989, p. 23), en detrimento de las sabidurías milenarias como el taoísmo, que han dejado gran impronta en sus diversas narrativas, que comprenden leyendas, mitos y fábulas. En efecto, en los relatos y narraciones taoístas, se puede rastrear la experiencia humana concreta del hombre de la antigua China, inmerso en un

5 El vocablo "crisis", del griego kpíøıs, hace referencia a una coyuntura de cambios en cualquier aspecto de una realidad organizada pero inestable, sujeta a evolución; especialmente, la crisis de una estructura. Los cambios críticos, aunque previsibles, tienen siempre algún grado de incertidumbre en cuanto a su reversibilidad o grado de profundidad, pues si no serían meras reacciones automáticas como las físico-químicas. Si los cambios son profundos, súbitos y violentos, y sobre todo traen consecuencias trascendentales, van más allá de una crisis y se pueden denominar revolución. Las crisis pueden ocurrir a un nivel personal o social. Pueden designar un cambio traumático en la vida o salud de una persona o una situación social inestable y peligrosa en lo político, económico, militar, etc. También puede ser la definición de un hecho medioambiental de gran escala, especialmente los que implican un cambio abrupto. De una manera menos propia, se refieren con el nombre de crisis las emergencias o las épocas de dificultad.

6 Lo narrativo ubica la vida como un autorrelato en relación con el mundo externo, es en palabras de Bruner y Ricoeur, un medio de inventar el propio yo, de darle una identidad (narrativa). En su expresión superior (autobiografía) es también elaborar el proyecto ético de lo que ha sido y será la vida (Bolívar, 1999). mundo fantástico, místico-espiritual ligado a las fuerzas del cosmos, en unas coordenadas de espacio-tiempo sujetas a las fuerzas del yin y del yang ${ }^{7}$ (Gómez, 2009, p. 70), centrado en su experiencia de unión con el "tao". En dichos relatos, se evidencia la necesidad de seguir "un orden cósmico", para vivir con armonía y tranquilidad. El desorden se produce justamente cuando dichas fuerzas entran en contradicción provocando la crisis, la cual se constituye en oportunidad de cambio y transformación para el mismo ser humano.

Así como en los relatos populares de las grandes culturas del mundo ${ }^{8}$, en la tradición taoísta, se cuentan ${ }^{9}$ historias que se

7 El yin yang es un concepto fundamentado en la dualidad de todo lo existente en el universo según la filosofía oriental en la que surge. Describe las dos fuerzas fundamentales aparentemente opuestas y complementarias, que se encuentran en todas las cosas. En todo se sigue este patrón: luz/oscuridad, sonido/silencio, calor/frío, movimiento/quietud, vida/muerte, mente/cuerpo, masculino/femenino, etc. El yin es el principio femenino, la tierra, la oscuridad, la pasividad y la absorción. El yang es el principio masculino, el cielo, la luz, la actividad y la penetración. Según esta idea, cada ser, objeto o pensamiento posee un complemento del que depende para su existencia y que a su vez existe dentro de él mismo. De esto se deduce que nada existe en estado puro ni tampoco en absoluta quietud, sino en una continua transformación. Además, cualquier idea puede ser vista como su contraria si se la mira desde otro punto de vista. En este sentido, la categorización solo lo sería por conveniencia. Estas dos fuerzas, yin y yang, serían la fase siguiente después del Tao, principio generador de todas las cosas.

8 Las culturas de todos los tiempos tuvieron deseos de contar sus vidas y experiencias, así como los adultos tuvieron la necesidad de transmitir su sabiduría a los más jóvenes para conservar sus tradiciones y su idioma, así como para enseñarles a respetar las normas ético-morales establecidas por su cultura ancestral, puesto que los valores del bien y del mal estaban encarnados por los personajes que emergían de la propia fantasía popular. Es decir, en una época primitiva en que los hombres se transmitían sus observaciones, impresiones o recuerdos, por vía oral, de generación en generación, los personajes de los cuentos eran los portadores del pensamiento y el sentimiento colectivo.

9 Etimológicamente, la palabra "cuento", procede del término latino computare, que significa contar, calcular; esto implica que originalmente se relacionaba con el cómputo de cifras, es decir que se refería, uno por uno o por grupos, a los objetos homogéneos para saber cuántas unidades había en el conjunto. Luego, por extensión pasó a referir o contar el mayor o menor número de circunstancias, es decir, 
refieren a la crisis o al fracaso de las tentativas humanas, a la vez que a sus éxitos y triunfos sobre los infortunios del destino; en este sentido, se legitiman formas de pensar, así como instituciones sociales o religiosas o se simbolizan modelos de composición de las mismas. Por otra parte, estos relatos, definieron muchas veces los criterios de comportamiento, de jerarquía social y de competencias en las sociedades en que se encontraban ${ }^{10}$. Prueba de ello, son las múltiples representaciones narrativas de la tradición taoísta, que permiten diversos juegos de lenguaje: normativos, denotativos, interrogativos, etc. La misma narración taoísta, puede tener reglas que fijan el decreto o ley natural que los seres humanos deben acatar para lograr un fluir continuo con el mismo cosmos (Gómez, 2010, p. 13).

Las fórmulas narrativas taoístas establecen un marco que muchas veces indica la autoridad de la que viene ese mensaje: el Tao ${ }^{11}$, eterno e inmutable, ley natural que rige el destino de los hombres (Lao Tsé, 1985, p. 21). En este caso, el narrador no es la autoridad que legitima el mensaje mismo, sino que declara la autoridad que lo legitima a

lo que ha sucedido o lo que pudo haber sucedido, y, en este último caso, dio lugar a la fabulación imaginaria" (Cáceres, 1993, p. 4).

10 Hans-Georg Gadamer ha sido quien mejor ha contribuido a fundamentar la nueva ontología que subyace a la epistemología. Así, en unas reflexiones sobre su gran obra Verdad y método (Gadamer 1992), afirmaba que la sociedad humana vive en instituciones que aparecen determinadas por la autocomprensión interna de los individuos que forman la sociedad [...] No hay ninguna realidad social, con todas sus presiones reales, que no se exprese en una conciencia lingüísticamente articulada (Gadamer, 1992, pp. 232, 237).

11 El tao se refiere a la esencia primordial 0 al aspecto fundamental del universo; es el orden natural de la existencia, que en realidad no puede ser nombrado, en contraste con las incontables cosas que se nombran y en las que se manifiesta la misma energía. Tao es un concepto metafísico originario del libro del Tao Te King y del taoísmo, aunque también se usa ampliamente en el confucionismo y el budismo chan (zen en japonés) y en la religión y la filosofía china. La palabra en sí puede traducirse literalmente por el camino, la vía, o la ruta, o también por el método o la doctrina. En japonés se le llama Do. su propia vista y a la del receptor del relato: el gran tao ${ }^{12}$, eterno e inmóvil, imperecedero e infinito (Watts, 2006, p. 57). Así, los relatos taoístas, en sí mismos, comunican las reglas básicas que debe seguir el hombre en sociedad, a la vez que indican el camino correcto para estar en armonía con el mismo cosmos. El relato se autoriza a sí mismo a través de diversas maneras narrativas, como en todas las culturas antiguas, transmitiéndose de una persona a otra, cumpliendo con su misión didáctica y sapiencial: para ser buen emisor, hay que experimentar previamente ser buen receptor, esta es la base de la transmisión cultural del saber tradicional taoísta desde la lejana historia de China antigua.

Por otro lado, pensadores como Frijot Capra y Thomas Berry ${ }^{13}$ han hecho referencia directa al taoísmo; concretamente Capra ${ }^{14}$, en El Tao de la física (1975), compara el conocimiento racional con el intuitivo; ejemplo de ello, es la física en donde se utiliza el método científico y como técnica la experimentación; en el caso de la intuición, los

12 Según la cosmovisión del taoísmo, El Gran Tao es la fuente de orientación de todo el proceso evolutivo del universo más allá de aquello que existe y no existe y anterior al espacio y el tiempo. El Tao es el principio que ordena todo, tras el incesante flujo de cambio, siendo así el origen de todo. Debido a esto, también es la constante que abarca todos los aspectos de la realidad, por lo que en este sentido se lo puede comparar con el concepto de "totalidad" de la filosofía occidental, aunque en occidente se lo ha personificado con representaciones más racionalistas y algunas teístas.

13 Thomas Berry, en su obra The dream of the Earth (1998), afirma que los seres humanos tenemos libertad de elección, pero parecemos estar aún buscando nuestro lugar en el cosmos, cuando ya lo tenemos. Según Berry, mucha de la presión para resolver los acertijos de la vida, provienen del hecho de que tratamos de encontrar nuestra solución como entidades separadas de otros contextos y pretendemos que podemos sobrevivir sin integrarnos a una red que nos engloba a todos. Pero la vida es una suma de interconexiones, y justamente, son estas interconexiones las que la hacen posible; todos dependemos de todos y del mundo natural que nos rodea.

14 Concretamente, Capra, en sus estudios, concibe el organismo como un sistema viviente desde la misma forma, y desde esta perspectiva intenta generar conciencia de los límites y reglas para el desarrollo y la ilimitada capacidad de creatividad del uso de los recursos. 
niveles de percepción de la realidad son más profundos y espirituales. Igualmente, este autor y científico, en la tercera parte del libro, plantea los siguientes paralelismos: la unificación del hombre con el cosmos, la dualidad yin yang, la unidad onda-partícula, el espacio tiempo como creaciones de la mente, la naturaleza dinámica del universo, la teoría del campo unificado y la relación vacío y forma, la danza cósmica y la naturaleza dinámica de la materia y el cambio, como lo presenta el Libro de las mutaciones o I Ching (Capra, 1975, pp. 42-57).

\section{EL ANÁlisis NARRATIVO COMO MÉTODO EMPLEADO EN EL ESTUDIO DE LOS RELATOS TAOÍSTAS}

Para los fines que se persiguen en este trabajo investigativo, se utilizará el método denominado "análisis narrativo"15 o crítica literaria; este consiste en el estudio del texto tradicional, tomado de una buena traducción, en este caso del chino mandarín. El análisis narrativo se apoya básicamente en el estudio de la composición empleada por los posibles redactores de los textos, en este caso las leyendas o historias taoístas, buscando entender y captar cuál es el recorrido que el texto en sí nos propone, para llegar a comprender la línea narrativa del texto. En este método se utilizan una serie de instrumentos que se pueden sintetizar en: demarcación del texto, análisis del entramado verbal de la narración, posible intención que subyace en la historia o en el discurso

15 El análisis narrativo, en cuanto a sus inicios va de la mano de los avances de la crítica literaria y los estudios en el campo de la lingüística, se comenzó a desarrollar en los años cuarenta por Wellek y Warren, sin embargo fue por los años setenta y ochenta que este método tuvo su auge concretamente en el estudio literario de los textos bíblicos, comenzándose a hablar de la narratología, término que acuñó por primera vez Todorov en 1969. y el espacio-tiempo, en que se desarrolla. En cuanto a las etapas del análisis narrativo se podrían enumerar: estudio de la trama, subdivisiones de la misma, estudio de personajes, análisis del narrador o narradores, así como de la misma narración y de los posibles lectores u oyentes. Después se pasa a estudiar el proceso interpretativo de lectura del texto (Kushner, 1989, p. 135).

Muchos autores, entre ellos Wellek y Warren (1974), concuerdan en decir que el análisis narrativo, propone un método de comprensión y de comunicación que corresponde a las formas de relato y de testimonio de las culturas ancestrales o tradicionales como las del Lejano Oriente. Por otra parte, el análisis narrativo dio origen a diversas escuelas que se ocuparon del estudio de algunas áreas concretas dentro de la narrativa, entre las principales se distinguen, el estructuralismo, la semiótica y la retórica.

Por otra parte, el análisis narrativo mismo, gravita en cimientos que se han constituido como distintas vertientes de estudio dentro del método literario y asevera que cuando se lee una obra estamos ante un mundo de imaginación: entre este y el mundo real siempre hay vínculos, puesto que el mundo real es la matriz primordial de la obra, no se trata de una deformación, sino de la creación de una nueva realidad, como en el caso de las narrativas del Lejano Oriente. Por otro lado, atiende al fenómeno de la "plurisignificación", la cual incluye la connotación: en el lenguaje literario el signo es portador de muchas dimensiones semánticas, ello hace posible esa multiplicidad de significaciones. La plurisignificación se manifiesta en dos formas: diacrónico o vertical, en donde los significados se adhieren a la vida de las palabras y sincrónico u horizontal, en 
donde la palabra adquiere significaciones gracias a las relaciones que mantienen con su contexto verbal. En este caso, palabra es un recurso que se enriquece con los elementos externos a ella (Garrido, 1996, p. 67).

\section{LA RELATIVIZACión DE LA CRISIS EN LAS LEYENDAS TAOÍSTAS}

"Cualquier cosa que suceda en cualquier parte del universo, puede afectar de manera instantánea todas las cosas que ocurran en cualquier otra parte del universo".

Teorema de Bell

El tema de la crisis $^{16}$, como experiencia y realidad humana, es recurrente en las leyendas y cuentos taoístas. En múltiples relatos cortos, se presentan variantes del tema, pero hay dos especialmente frecuentes, que son formas de mostrar la enseñanza que transmite el sabio o el maestro sobre el sentido de la crisis y el camino que hay que seguir para superarla o sobre la interpretación que se debe hacer de esta, desde un sentido trascendente. La primera de estas formas es la pregunta directa al maestro, quien dará una respuesta, sorprendente a veces, pero que invita siempre a la reflexión, mostrando a su vez enorme sabiduría. De la misma forma, algunas de estas historias de larga tradición, son muy pertinentes para comunicar conceptos, valores, principios o ideales. Empecemos con un conocido cuento ${ }^{17}$

16 En los ideogramas del chino-mandarín, la palabra "crisis" es sinónimo de "oportunidad". En cada crisis hay una oportunidad, aún más profunda que la misma pérdida o el mismo conflicto. La crisis es una situación en la que los patrones en vigor quedan rotos por acontecimientos nuevos y en cierto modo, inesperados, lo cual genera una perturbación, perjuicios para muchos y oportunidad para otros.

17 En términos generales, el cuento es una narración de lo sucedido 0 de lo que se supone sucedido (Varela, 2001). Esta definición admite dos posibilidades aplicables a la forma y el contenido: cuento sería taoísta, especialmente adecuado para comentar cómo relativizar la crisis desde una visión diferente de la mera emocionalidad o sublimación racional de los acontecimientos:

El campesino y su caballo:

Había una vez un campesino sabio y su hijo que vivían en un pueblo de la Antigua China con su caballo. Un buen día el animal se les escapó y los vecinos del pueblo vinieron a consolarles por su mala suerte, pero el campesino les dijo:

- El único hecho cierto, hoy aquí, es que se ha escapado un caballo. Si eso es buena o mala suerte, el tiempo dirá.

Unos días después el caballo retornó con una yegua, y los vecinos del pueblo felicitaron al campesino y a su hijo por su buena suerte. Como la vez anterior el campesino les dijo:

- El único hecho cierto, hoy aquí, es que el caballo ha vuelto con una yegua. Si eso es buena o mala suerte, el tiempo dirá.

Al cabo de un tiempo, el hijo del campesino, intentando domar a la yegua salvaje, se cayó y se rompió una pierna. El médico dictaminó que se quedaría cojo de por vida. Los vecinos fueron a casa del campesino y de su hijo para consolar a este último, consternado por su mala suerte. Una vez más el campesino dijo:

- El único hecho cierto, hoy aquí, es que mi hijo se ha roto una pierna. Si eso es buena o mala suerte, el tiempo dirá.

Entonces comenzó una cruenta guerra en el país y un grupo de guerreros vinieron a reclutar de manera obligatoria a todos los jóvenes del pueblo. Cuando se disponían a alistar al hijo del cam-

la narración de algo acontecido o imaginado. La narración expuesta oralmente o por escrito, en verso o en prosa. Cuento es lo que se narra, de ahí la relación entre contar y hablar (fabular, fablar, hablar). 
pesino se fijaron en que este cojeaba de una pierna:

- ¿Qué te pasa en la pierna? - preguntó el jefe de los guerreros.

- Me caí de una yegua mientras intentaba domarla. Nunca más podré caminar derecho o correr - contestó el hijo del campesino.

- Así no nos sirves. Necesitamos hombres fuertes para combatir, harás mejor en quedarte con tu padre y tu mujer dictaminó el jefe.

\section{El campesino dijo:}

- ¿Lo entiendes ahora, hijo mío? Los hechos no son ni buenos ni malos en sí mismos, lo que nos hace sufrir son las opiniones que tenemos de ellos. Hay que esperar a ver cómo afectan a nuestro devenir. Un día maldijiste tu pierna y ahora es ella la que te ha salvado de una muerte cierta. Para bien o para mal las cosas simplemente suceden (Cheng Zhen, 2002, p. 32).

En este popular cuento taoísta, se da un interesante juego de subjetividades en un proceso dialógico, que se convierte en un modo privilegiado de construir reflexión y conocimiento acerca de la experiencia de la crisis. De esta manera, emerge con toda su fuerza, la materialidad dinámica del sujeto, sus dimensiones personales (afectivas, emocionales y personales), que solo pueden expresarse por una narrativa de alguna manera autobiográfica (Chamberlayne, Bornat y Wengraf, 2000), y que podríamos leer desde la experiencia de una persona concreta (el campesino) y sus interacciones familiares y sociales.

Al no ser narrada la historia desde ideas conceptuales o de corte lógico, las cuales no causan tanto impacto en el oyente, sino que son transmitidas en una narración de fácil acceso, adquiere una mayor relevancia e impregna más profundamente las emociones del destinatario del mensaje, ya que se involucra, en este caso, en la historia del campesino y él mismo, se siente partícipe en la interpretación de la misma narración. El oyente o lector no se enfrenta a una afirmación indiscutible (la pérdida o el fracaso de un animal o el accidente del hijo), sino que se le ofrece una vía de reflexión para ver más allá del problema, una posible solución.

Al hacer un análisis de la historia del personaje del cuento, que entra en crisis por la pérdida de su caballo, es bueno recordar que la misma palabra "crisis"18 en chino, no necesariamente contiene una idea negativa. Algunos de sus significados - el primero entre ellos - más bien, se refiere a un punto de inflexión o de desviación en un asunto o proceso, del que tanto puede resultar algo bueno o algo malo; en este caso en las palabras del campesino, la experiencia queda abierta a las elecciones humanas y "aún a las predestinaciones de las fuerzas trascendentales, tema propio de la sabiduría oriental" (Guenon, 2002, p. 14).

Quizá en esta historia, lo negativo de la pérdida del caballo y en el accidente del hijo, sea la incertidumbre, que está siempre presente en la misma crisis: cambio brusco en el curso de una enfermedad o pérdida, ya sea para mejorarse o encontrarse, ya para agravarse o perderse. La transformación o mutación importante que puede surgir en el desarrollo de la historia, pueden ser

18 En los ideogramas del chino-mandarín, la palabra "crisis" es sinónimo de "oportunidad". En cada crisis hay una oportunidad, aún más profunda que la misma pérdida o el mismo conflicto. La crisis es una situación en la que los patrones en vigor quedan rotos por acontecimientos nuevos y, en cierto modo, inesperados, lo cual genera una perturbación, perjuicios para muchos y oportunidad para otros. 
otros procesos que están implícitos en esta y que apuntan al orden físico (enfermedad o salud), económico (pobreza o riqueza), histórico (la guerra o la paz) o a los valores espirituales (el amor, la fe y la esperanza).

En estas contingencias de la vida, la crisis se presenta como una situación o como un proceso que permite tomar decisiones cuando está en duda la continuación, modificación o cese de una actividad o un estado de vida. En los momentos decisivos de una crisis grave (guerra, enfermedad, en este caso) y de consecuencias importantes en contexto de crisis (pérdida o ganancia); de esta manera, el ser humano se enfrenta a sus propios juicios y creencias $^{1}$, como el campesino frente a sus convicciones frente a la relatividad de los sucesos considerados favorables o desfavorables y en donde se presenta la oportunidad para aprender a tomar nuevas decisiones o para hacer nuevas opciones después de haber examinado cuidadosamente las situaciones que lo generan (ley de causa-efecto, predestinación o el libre albedrío), "llegando a relativizar los mismos resultados (buenos o malos) que se obtienen en el trascurso de la vida" (Becerra, 2011, p. 34).

Por otra parte, aplicando lo que afirman Santamaría y Ramírez (2009), emerge en esta historia de El campesino y su caballo, el llamado modo narrativo (sintagmático), caracterizado por presentar la experiencia concreta humana como una descripción de las intenciones, mediante una secuencia de eventos en tiempos y lugares, en donde los relatos narrativos son los medios privilegiados para generar conocimiento y encuentro (Huberman, Thompson y Weiland,
2000). En este caso, el encuentro que tiene el campesino con sus vecinos, con los soldados que reclutan jóvenes, con su mismo hijo, expresa con toda su fuerza, el potencial de la riqueza humana en relación con otros seres (caballo) y con su mismo entorno (el campo), "aspectos claves en la dinámica taoísta de integración hombre-naturaleza" (Vallejo y Gómez, 2009, p. 47). Se corrobora, por tanto, en esta legendaria historia que el modo narrativo es cualitativamente diferente a otros, al centrarse en los sentimientos, vivencias y acciones dependientes de contextos específicos en donde se desenvuelve el drama humano; lejos del frío y neutro conocimiento científico, en el cual las voces de los protagonistas como el investigador e investigado, aparecen silenciadas, en las narrativas taoístas (al modo de todas las del Lejano Oriente), "por el contrario, los sujetos cobran vida e intercambian experiencias y sentimientos" (Maspero, 2000, p. 31).

Finalmente, en este tipo de conocimiento narrativo, plasmado en la historia de $E l$ campesino y su caballo, se observa otra forma legítima de construir conocimiento, que no debe ser recluido al ámbito de las solas expresiones emotivas (que de hecho tienen su peso protagónico), sino que también se recrean los textos narrativos de la misma historia, de modo que el lector u oyente, puede "experimentar", "las vidas o acontecimientos narrados en ella, llegando incluso, a identificarse con situaciones o personajes concretos" (Vila y Galvany, 2006, p. 67).

Ahora, se verá otra interesante leyenda de las narrativas tradicionales del taoísmo, en la que se continúa reflejando la visión que sobre la misma crisis tiene el taoísmo: 


\section{El rey y el miedo}

Un rey famoso por su coraje y ecuanimidad, perdió casi todo su reino y hasta el último de sus soldados como consecuencia de los violentos ataques y saqueos de las hordas bárbaras. No le quedaban más que dos servidores y su castillo era el último bastión que impedía a los conquistadores dominar sus territorios y esclavizar las aldeas diezmadas por el continuo acoso. Llegó el día en que se supo que los bárbaros avanzaban hacia las puertas de la ciudad con la intención de poner cerco al palacio. Se cuenta que esa noche, cuando llegaron las noticias del avance enemigo se vio el rostro del monarca marcado por el temor y la responsabilidad, pero en ningún momento abatido por el miedo.

$\mathrm{Al}$ amanecer el rey ordenó a sus servidores que abrieran todas las puertas y ventanas, y acto seguido se instaló en una de las almenas a fin de observar la llegada de los invasores. Inmutable, les vio avanzar hasta la escalinata de palacio. Pero su serenidad, perturbó hondamente a los bárbaros. Estos supusieron que les esperaba una trampa en su interior. En vez de poner cerco a aquel lugar, el jefe reunió a sus hombres y tocó la retirada.

El rey dijo entonces a sus servidores: - Ved, y no olvidéis nunca que, una misma emoción, el miedo, a ellos les ha impulsado a huir atemorizados y a nosotros nos ha motivado a permanecer en nuestro puesto, encontrando una respuesta creativa a tan atemorizante situación (Cheng Zhen, 2002, p. 45).

En esta interesante historia, cuyo protagonista está representado por el poder (real) se evoca de nuevo el tema de la crisis, esta vez dada por la coyuntura de la guerra, tema igualmente recurrente en la época de la China de las dinastías imperiales. De la misma manera, emerge el tema del miedo como elemento importante en la narrativa tradicional taoísta y que parte de una situación de crisis en las que las acciones humanas, aparentemente son únicas y no repetibles, evocan esta emoción que se caracteriza por un intenso sentimiento habitualmente desagradable, provocado por la percepción de un peligro, ya sea presente o futuro, real o supuesto. El miedo, es puesto en escena en este relato, al surgir una situación concreta de amenaza y aparece como una de las emociones primarias que se deriva de la aversión natural a la amenaza, presente en todos los seres humanos (rey, soldados, enemigos); a la vez, es un esquema adaptativo y supone un mecanismo de supervivencia y de defensa que permite al individuo responder ante situaciones adversas (el ataque al palacio real) con rapidez y eficacia, como estado afectivo y emocional (temor, emoción, intranquilidad), necesario para la adaptación del organismo al medio.

Es bien diciente la frase colocada, en boca del rey, en la parte final de la narración refiriéndose al miedo: "a ellos les ha impulsado a huir atemorizados y a nosotros nos ha motivado a permanecer en nuestro puesto, encontrando una respuesta creativa a tan atemorizante situación". Ante la misma realidad existencial del miedo, quizá la primera clave consiste en valorar adecuadamente el miedo: ¿en qué consiste? ¿Cómo afrontarlo con serenidad y ecuanimidad?, la frase del rey sobre el miedo, supone el conectarse con una oportunidad para vincularse con la parte más creativa, más original, más auténtica de cada ser humano. Se diría en la dinámica de la narrativa taoísta, que es una oportunidad para establecer una relación cualitativamente distinta, tanto con el hombre mismo como en su relación con la misma naturaleza. La actitud del rey, en 
esta interesante narración taoísta, por otra parte, nos lleva a pensar en la importancia de no juzgar, no exigir, no criticar al miedo, sino por el contrario, tratar de acercarse a él para entenderlo, aprendiendo su real significado, finalmente afrontarlo con éxito en una situación de crisis. ¿Debe pasar de igual manera frente a la realidad de la crisis por parte del ser humano?

De esta manera, recurriendo a lo afirmado por Bruner (1988), que mencionaba sobre la construcción del relato desde dos paisajes simultáneamente: el paisaje exterior de la acción y el paisaje interior del pensamiento y las intenciones, en este caso, de la narración de El rey y el miedo, se encontraría entonces, en que hay un doble discurso referido a la crisis: el de los hechos o acontecimientos (el ataque de los enemigos a un reino, y lo que cada personaje piensa y siente ante los mismos acontecimientos externos (miedo, temor, angustia).

En el caso concreto de esta narración sobre El rey y el miedo, además de esta función referencial (que describe el estado de cómo son los acontecimientos que envuelven la misma experiencia del miedo), hay una función modal (lo que se piensa de la experiencia del ataque y del miedo) e, incluso, una función de acto (cuando se altera el estado emocional-racional del oyente, que asume una posición frente a la experiencia de crisis generada por el miedo). Ahora bien, si el primer tipo de discurso (el de los hechos o acontecimientos), con función referencial, puede ser categorizado; el segundo, más modal, no se deja atrapar con categorías temáticas ya que corresponde al orden subjetivo. He aquí el éxito que tienen las narraciones taoístas que no se dejan "reducir" simplemente a una sola interpretación lógico-racional.

Por otra parte, en esta narración, en cuanto al aspecto social y cultural, ligando el tema del miedo al de la crisis, se puede decir que ambos elementos, forman parte del carácter no solo de una persona sino de toda organización social, incluso, como afirma el rey a sus súbditos, el miedo, posee un componente educativo: nos enseña a ser más asertivos y creativos; por tanto, se puede aprender incluso a no temer, no obstante, el ser humano empodera el miedo como parte de sus aprendizajes. De igual manera, el miedo aparece como una modalidad del género narrativo: socialmente, tener miedo es normal, pero cuando se pregunta por el cómo, cuándo y hasta dónde es pertinente tener miedo, se refiere a su comprensión pedagógica; esto es algo que se puede ir deduciendo del análisis de cada elemento de la narración taoísta.

Finalmente, con referencia a esta leyenda de El rey y el miedo, en todo el proceso de comprensión, reconstrucción y afrontamiento del miedo, el verdadero protagonista es "el niño interior", que cada uno lleva dentro: tenemos que dejar que hable este niño interior y a su vez formar parte activa del mismo cuando se afronta la crisis en la experiencia presente (León, 2007, p. 21). Uno de los errores más comunes es intentar dar una solución estereotipada e intentar acallar a dicho niño: el nivel de compresión del mismo niño y de sus motivaciones, intereses y acuerdos internos, ayuda a observar la realidad específica del miedo, intuyéndola desde una perspectiva diferente, reconstruyendo el significado del mismo miedo, a partir de elementos útiles (que pueden ser lógicos e ilógicos, reales e imaginarios). 
A continuación, se analizará una tercera leyenda taoísta que hace alusión al tema de la crisis desde otra interesante faceta del pensamiento taoísta y que de muchas maneras, contribuye a una nueva comprensión del tema en la época contemporánea.

\section{El músico Wen aprende a tocar el laúd}

Hace mucho tiempo había un músico que podía encantar a pájaros y peces haciéndolos bailar con su música. Un músico que tocaba el laúd llamado Wen, del reino de Cheng, oyó esta historia y quiso aprender esa habilidad. Así pues, abandonó a su familia y se fue a estudiar con el maestro músico Hsiang. Durante mucho tiempo, Wen no pudo tocar nada. Sus dedos se agarrotaban y cada vez que tomaba el laúd no era capaz de tocar. Después de tres años no había aprendido nada. "Deberías volver a tu casa" - le dijo el maestro. Wen puso su laúd en el suelo, asintió y dijo: "No es que no haya aprendido ninguna canción o que no pueda afinar mi instrumento adecuadamente. Lo que ocurre es que no puedo tocar desde mi corazón y por ello la música nunca se ha convertido en parte de mí. Esta es la razón por la que no me puedo animar a tocar. Déjame descansar un poco y veamos qué ocurre".

No mucho después, Wen volvió a su maestro. ¿Cómo te va con tu música? -le preguntó el maestro. - Creo que he dado un salto adelante. Déjame que te lo muestre.

Wen tomó el laúd y con suavidad acarició la cuerda llamada Otoño. Aunque era primavera soplaba un viento fresco, y las hojas crujían mecidas por la brisa de otoño, y el cielo estaba brillante y sin nubes. Después, en otoño, tocó la cuerda llamada Primavera y se produjo una suave brisa. Cayó una lluvia cálida y se abrieron las flores. En medio del verano, Wen tocó la cuerda llamada Invierno, y de repente cayó nieve y los ríos helaron. Cuando llegó el invierno, tocó la cuerda llamada Verano, inmediatamente brilló el sol con fuerza, desapareció la nieve y se fundió el hielo de los ríos.

Finalmente, cuando tocó la última cuerda junto con todas las demás, sopló una brisa refrescante, aparecieron flotando nubes celestes, cayó un dulce rocío en el suelo y brotaron manantiales fragantes. El maestro músico Hiang se golpeó el pecho exclamando: - Tu música supera con mucho cualquier palabra que pueda describirla. Los mejores músicos tendrán que aprender de ti a partir de ahora (Cheng Zhen, 2002, p. 21).

Las historias de encuentros entre maestros y discípulos y sus diálogos son muy sugerentes y significativos en China y "están cargados de sentido trascendental y a la vez práctico" (Brosse, 1999, p. 34). En esta interesante historia de la tradición taoísta, narrada en el contexto maestro-discípulo, se puede observar cómo desde la perspectiva del Tao, todas las cosas se elevan, se vuelven grandes y luego retornan a su raíz (esto plasmado en la narración de las estaciones que vienen y pasan). Vivir y morir es simplemente entrar y salir, como cuando el protagonista toca el laúd y van fluyendo las estaciones con sus diversos fenómenos: la brisa, la nube, la nieve, el calor, el aire. El tema de la crisis, esta vez, emerge desde la imposibilidad del discípulo, Wen, de tocar el laúd al modo prodigioso del maestro (Hsiang).

Las fuerzas de la naturaleza en esta narración, son conjuradas desde la fuerza de la música (elemento primordial en la transformación espiritual del ser humano en las culturas orientales). El poder que se atribuía a la música, hizo que se considerara a la 
misma como un arma imprescindible para lograr el equilibrio de los seres humanos con ellos mismos y con la naturaleza. Confucio afirmaba que "era posible mantener el orden y las costumbres en la sociedad por medio de la música que llevaba a la experiencia espiritual" (Tucci, 2007, p. 34). Por otra parte, esta narración, hace alusión al valor de la música (representada en el arte de interpretar el laúd), el cual va más allá del mero acompañamiento en los rituales y está ligada al equilibrio y armonía de la energía del universo y "también de las fuerzas interiores de cada individuo, tema tan propio de la tradición taoísta" (Radakhrisna y Rajú, 2001, p. 57).

Ahora bien, el esquema del maestro que enseña a su discípulo y deja una moraleja, es alterado en este relato para dar cabida al protagonismo del mismo discípulo (Wen). En la mayoría de las narrativas orientales, “el maestro es aquel que lleva al discípulo a escuchar las melodías de su propio ser interior" (Tagore, 1994, p. 34). La frase de Wen: "Lo que ocurre es que no puedo tocar desde mi corazón y por ello la música nunca se ha convertido en parte de mí", es la clara alusión al discípulo que ha asumido seriamente el papel de entrar en su propio interior para conocerse y transformarse.

Por otra parte, en esta narración taoísta, hay implícito otro importante elemento que hace relación al tao, como elemento autocontenedor de todas las cosas, se trata del "camino del no-ser que lleva a la quietud y la observación" y que a su vez conduce de lo múltiple a lo Uno. En la historia tanto el maestro (Hsiang) como el discípulo (Wen), llegan desde su propia experiencia a la conclusión de que para poder recorrer el camino del tao, hace falta preparación interna: mediante la práctica constante, el esfuerzo, la perseverancia, el recogimiento y el silencio (aspectos necesarios en el arte de aprender un instrumento), se llega a un estado de relajación que lleva a sentir el arte de la música: aún más, para sentir aquella música que procede de interpretar el laúd, es primordial, antes escuchar la propia armonía interior ${ }^{19}$.

Por último, en el caso concreto de esta narración, El músico Wen aprende a tocar el laúd, se puede entender la función referencial, en los pasos que sigue el mismo Wen, para alcanzar la destreza que requiere la interpretación del laúd y en los acontecimientos que van tejiendo la misma experiencia de encuentro con su propio ritmo interior; de la misma manera, se explicita la función modal, en lo que piensa Wen es su propia experiencia del aprendizaje del laúd y lo que puede representar dicha experiencia su propia vida; además se percibe una función de acto (cuando los mismos lectores $\mathrm{u}$ oyentes, van alterando sus estados, tanto emocionales como racionales, asumiendo una postura personal frente a la narración). Como en la anterior historia, El músico Wen aprende a tocar el laúd, el éxito que posee la narración es su función modal, la cual no se deja encasillar por categorías temáticas ya que corresponde al orden subjetivo, de tal suerte que la historia, no se deja "someter" sencillamente a una sola interpretación de corte lógico-racional y más bien permite múltiples interpretaciones por parte de los lectores u oyentes.

19 Según el taoísmo, la meta del tao como camino, es llegar a este estado de contemplación y equilibrio, de serenidad y fortaleza interior, pues se posibilita la contemplación del Ser interior, del alma, y así se logra ver lo invisible, escuchar lo inaudible, sentir lo inalcanzable. 


\section{Conclusiones: APORTES PARA} LA REFLEXIÓN ACTUAL SOBRE LA CRISIS DESDE LAS NARRACIONES TAOÍSTAS

Una vez vistos algunos relatos de la tradición taoísta, a continuación se realizará un análisis de los posibles aportes que se pueden releer desde los mismos, para la época contemporánea, especialmente en una sociedad en crisis generalizada, desde los modos paradigmáticos establecidos hasta la misma relación del hombre con su entorno, donde se replantea el papel del sujeto transformador del entorno y la necesidad de incluir la subjetividad en el proceso de comprensión de la realidad.

Tanto las narrativas tradicionales como las narrativas actuales, se funden productivamente para comprender la compleja realidad sociocultural contemporánea, especialmente, en un mundo "donde los criterios habituales (validez, generalización, fiabilidad) de legitimación, han empezado a moverse" (Alimonda, 2003, p. 58). La investigación narrativa de hoy, incrementa dicha crisis introduciendo una "fisura" entre la experiencia vivida y cómo debe representarse en el discurso de la investigación. Emerge, entonces, con toda su fuerza, la materialidad dinámica del sujeto, sus dimensiones personales (afectivas, emocionales y biográficas), que solo pueden expresarse por narrativas biográficas en ciencias sociales (Chamberlayne, Bornat y Wengraf, 2000).

Frente al fenómeno denominado "crisis", se deben analizar las muchas crisis que conmueven el mundo de hoy: del Estado, de la familia, de la economía, de la cultura, etc., las que no constituyen sino múltiples aspectos de una sola crisis fundamental, que tiene como campo de acción al propio hombre ${ }^{20}$. En otros términos, esas crisis tienen su raíz en los más profundos problemas del ser interior, de donde "se extienden a todos los aspectos de la vida social del ser humano contemporáneo y a todas sus actividades" (Gómez Romero, 1982, p. 87).

Las narraciones taoístas, analizadas anteriormente, nos hacen caer en cuenta que esta crisis no es solo del hombre occidental y cristiano, es decir, del europeo y de sus descendientes, sino "del ser humano en general: se trata de una crisis que afecta a todos los pueblos y naciones" (Montegut, 1982, p. 75); en cada una de ellas, tal crisis se complica con los problemas propios de las respectivas culturas y civilizaciones y con el choque entre estas y sus diversos factores. Por más profundos que sean dichos factores de diversificación de la crisis, se pueden mencionar cinco notas capitales de esta: es universal, "no existe hoy pueblo que no esté alcanzado por ella, en mayor o menor grado" (Cáceres, 1993, p. 45); es una en cuanto se trata de un conjunto de crisis que se desarrollan paralela y autónomamente en cada país, "pero están ligadas entre sí por algunas analogías más o menos relevantes" (Boff, 2002, p. 43). Es total, ya que se desarrolla en una zona de problemas tan profunda, que se prolonga o se desdobla, por el propio orden de las cosas, en todas las potencias del hombre y en todos. Es dominante, ya que desde los acontecimientos de nuestros días "parecen una maraña caótica e inextricable, y de hecho lo son desde muchos puntos de vista" (Antunes, 2002, p. 87). Es procesual, ya que no es un hecho

20 El ser humano en la era actual es el ejemplo clásico de una sociedad en medio del cambio, pese a que fuimos educados en la presunción de que el sistema de valores imperante iba a permanecer constante para siempre, nos encontramos en una disyuntiva en la que no sabemos aún cómo responder de manera apropiada. 
espectacular y aislado, sino que por el contrario, es un proceso con un vasto sistema de causas y efectos que, habiendo nacido, en determinado momento, con gran intensidad, en las zonas más profundas del alma y de la cultura del hombre occidental, viene produciendo, desde siempre hasta nuestros días, sucesivas convulsiones. Al respecto, el famoso pensador e historiador René Guenon, célebre impulsor del diálogo Occidente-Oriente, dice lo siguiente:

Por consiguiente, si se dice que el mundo moderno sufre una crisis, lo que se entiende por eso más habitualmente, es que ha llegado a un punto crítico, $\mathrm{o}$, en otros términos, que una transformación más o menos profunda es inminente, que un cambio de orientación deberá producirse inevitablemente en breve plazo, de grado o por la fuerza, de una manera más o menos brusca, con o sin catástrofe [...] Es también por eso por lo que los acontecimientos se desarrollan con esa velocidad acelerada a la cual hacíamos alusión primero; sin duda, eso puede continuar así algún tiempo todavía, pero no indefinidamente; e incluso, sin poder asignar un límite preciso, se tiene la impresión de que eso ya no puede durar mucho tiempo (Guenon, 2010, p. 5).

De la misma manera, el interés actual por los relatos y narrativa del lejano Oriente, en este caso por el taoísmo, puede ser visto como la expresión de una actitud crítica hacia la instrumentalización del conocimiento, como mera racionalidad técnica, o como mero formalismo científico, e incluso solo informativo. El interés por la narrativa oriental expresa el deseo de volver a las experiencias significativamente humanas (duda, miedo, coraje, altruismo, felicidad, amor), "que normalmente quedan excluidas de las reflexiones de corte científico actual" (Van Manen, 1994, p. 159), para tratar de hallar respuestas en medio de las épocas de crisis, tanto personal como socio-cultural. En el caso concreto de los cuentos taoístas analizados, la incorporación de elementos fantásticos, inexplicables y paradójicos, proyectan el texto más allá de la comprensión racional: la razón no es la única vía de acceso a la verdad absoluta (que se cuestiona dentro de cada relato), además, se plantea la inexistencia de una única verdad y se provoca cuestionamiento e incertidumbre en el lector.

Por otra parte, las narrativas taoístas, en relación con el tema de la crisis contemporánea, hacen reflexionar sobre algunos de los grandes temas de la narrativa actual: "la relación compleja y paradójica entre el ser humano-naturaleza" (Heisig, 1996, p. 31), el abandono y la desprotección de las zonas rurales; la crisis del hombre anónimo, "solitario, oprimido, masificado en las grandes ciudades" (Barrere, 1992, p. 43); los conflictos y las dificultades propios de la convivencia entre las personas de distintas clases sociales y la inserción de los foráneos e inmigrantes; "la crisis de gobernabilidad y los excesos de los gobernantes sumados a los agudos problemas de injusticia social y violencia sociopolítica y cultural" (Benjamin, 1993, p. 59).

Por último, en los relatos y narraciones taoístas, se evidencia la necesidad de seguir "un orden cósmico", para vivir con armonía y tranquilidad con la naturaleza. Ante la crisis actual que evidencia un alto componente de "desconexión" entre el hombre y el medio ambiente, "producto del desorden y de las fuerzas que entran en contradicción provocando la misma" (Barrere, 1992, p. 45), la misma sabiduría oriental, sigue proponiendo empoderar una nueva oportuni- 
dad de cambio y transformación para que el hombre entre en otra dinámica de creatividad, solidaridad y respeto por todos los seres que pueblan el planeta.

Por otro lado, no se debe olvidar que científicos como Bohm ${ }^{21}$, al proponer nuevas teorías como la del holograma (Bohm, 1988, p. 32) ${ }^{22}$, colocan a la ciencia en otra posición frente al género narrativo $\mathrm{y}$, en especial, ante las narrativas del lejano Oriente, "las cuales hablan de una "interconexión energética" entre todos los seres que pueblan el universo ${ }^{23}$, incluyendo a los seres humanos" (Gómez, 2010, p. 32). Así las cosas, la visión taoísta que propende por un equilibrio armónico producto del adecuado manejo de las fuerzas contrarias (yin-yang), contribuye a vislumbrar una nueva perspectiva en términos ético-espirituales, para el adecuado manejo de la crisis generalizada que afecta a los seres humanos y a la naturaleza en la época contemporánea. Si lo narrativo

21 David Bohm, conocido físico de la Universidad de Londres, dice que a pesar de su aparente solidez, el universo es en realidad una ilusión, un holograma gigantesco y quizá infinito. Es importante también recordar que un holograma es una fotografía tridimensional producida con la ayuda de un láser. Para crear un holograma el objeto a fotografiar viene primero sumergido en la luz de un rayo láser, luego a un segundo rayo láser se lo hace rebotar sobre la luz refleja del primero y el esquema resultante de la zona de interferencia dónde los dos rayos se encuentran es impreso sobre la película fotográfica.

22 Esta teoría, se acerca mucho a lo que afirmaban las antiguas tradiciones orientales, en especial la taoísta. En un universo hologrático hasta el tiempo y el espacio no serían más que principios fundamentales, ya que conceptos como la localidad (ubicación) son quebrantados en un universo donde nada está realmente separado del resto: también el tiempo y el espacio tridimensionales como así también las imágenes del pez sobre los monitores de TV, debería ser interpretados como simples proyecciones de un sistema mucho más complejo. A un nivel más profundo, la realidad no es otra que un tipo de superholograma, donde el pasado, el presente y el futuro coexisten simultáneamente.

23 Cada acción en el Universo trae una reacción, porque todo está correlacionado. Y los ritmos de respuesta de la naturaleza ante acciones del individuo y de la sociedad, están fijados también por la naturaleza, en secuencias predecibles de eventos relacionados sincrónicamente con los movimientos planetarios del sistema solar. posiciona la vida como un autorrelato en relación con el mundo externo, tal como lo afirma Ricoeur (1995), es importante que los seres humanos del siglo XXI, inventemos otras formas de darle salida a la profunda crisis generalizada en que vivimos desde nuevas miradas creativas e integradoras que, al ejemplo de las culturas milenarias como el taoísmo, hallen su justo anclaje en una permanente búsqueda de la verdad, del sentido de la responsabilidad y de la justicia, en un esfuerzo constante por autocomprenderse en el contexto de la naturaleza y en el deleite por el trabajo honesto y bien hecho, además de la aspiración a la trascendencia desde las realizaciones históricas en el "aquí y ahora", las cuales deben incluir una visión generosa sobre las dinámicas complejas y paradójicas en que se tejen los dramas del mundo actual.

\section{REFERENCIAS}

Alimonda, H. (2003). Ecología política: naturaleza, sociedad y utopía. Buenos Aires: Clacso.

Antunes, R. (2002). Ética, ciencia y medio ambiente. Madrid: Multiprensa.

Barrere, M. (1992). La tierra, patrimonio común. Barcelona: Paidós.

Becerra, J. (2011). Creencia narrativa y ciencia positiva. Razón y palabra, 14(66). Instituto tecnológico y de Estudios Superiores de Monterrey.

Benjamin, C. (1993). Diálogos sobre ecología, ciencia y ecología. Río de Janeiro: Nova Frontera.

Berzosa, R. (1995). Nueva era y cristianismo. Entre el diálogo y la ruptura. Madrid: BAC.

Blume, H. (1983). Gaia, una nueva visión de la vida sobre la tierra. Madrid: Tusquest. 
Boff, L. (2002). Grito de la tierra, grito de los pobres. Madrid: Trotta.

Bohm, D (1988). Ciencia, orden y creatividad. Barcelona: Kairos.

Borrero, J. (2002). Los derechos ambientales: una visión desde el Sur. En Ensayos de economía política. Cali: Cela.

Botero, M. (1983). Ecodesarrollo. Bogotá: Punma.

Bourdieu, P. (1999). La miseria del mundo. Madrid: Akal.

Bourdieu, P. (2002). La distinción. Criterio y bases sociales del gusto. México: Taurus.

Bourdieu, P. (2003). Sobre la televisión. Barcelona: Anagrama.

Brosse, J (1999). Los maestros Zen. Palma de Mallorca: José J. de Olañeta.

Bruner, J. (1988). Realidad mental, mundos posibles. Barcelona: Gedisa.

Cáceres, A. (1993, 7 de marzo). Las naranjas maquilladas de Néstor Taboada Terán. Presencia Literaria, 4(2).

Calvo, M. (1977). Periodismo científico. Madrid: Paraninfo.

Cañedo, R. (2004). Apuntes para una historia universal. Cuba: Ecimed.

Capra, F. (1975). El tao de la física. Barcelona: Humanitas.

Capra, F. (2002). Las conexiones ocultas. Barcelona: Anagrama.

Chamberlayne, P.; Bornat, J. y Wengraf, T. (Eds.) (2000). The Turn to Biographical Methods in Social Science: Comparative Issues and Examples. Londres: Routledge.

Cheng Zhen Ma (2002). Leyendas de China taoísta. En Sabiduría oriental. Barcelona: Paidós.

Eco, U. (1976). Tratado de semiótica general. México: Lumen - Nueva Imagen.
Fischl, J. (2002). Manual de historia de filosofía. Barcelona: Herder.

Fulcanelli (2000). Moradas filosofales. Madrid: España: Plaza \& Janés.

Gadamer. H. (1992). Verdad y método. Salamanca: Sígueme.

García-Noblejas, G. (2004). Mitología clásica china. Madrid: Trotta.

García-Noblejas, G. (2007). Mitología de la China antigua. Madrid: Alianza.

Garrido, A. (1996). El texto narrativo. Madrid: Síntesis.

Geertz, C. (1994). Conocimiento local. Ensayos sobre la interpretación de las culturas, Barcelona: Paidós.

Gómez, I. (1982). La filosofía y la crisis del hombre contemporáneo. Anuario Filosófico (15), 225-238. Barcelona: Ferrer.

Gómez, J. (2009). Aportes a la problemática ciencia-espiritualidad desde el B. Revista Hallazgos, 5(2).

Gómez, J. (2010). Hombre y naturaleza desde la visión del Lejano Oriente: apuntes para una reflexión sobre la crisis espiritual del hombre actual. Revista La Salle, núm. 56.

Gómez, J. (2010). Propuesta pedagógica basada en la relación hombre-naturaleza en el taoísmo ante la crisis ecológicoespiritual del hombre contemporáneo. Revista Hallazgos, 6.

Gómez, J. y Vallejo, C. (2011). Pensar y sentir desde la unidad, la diversidad y el movimiento: posible diálogo Occidente-Oriente. Bogotá: Ediciones USTA.

Guenon, R. (2010). La crisis del mundo moderno. Barcelona: Paidós.

Heisig, J. W. (1996). El cuento detrás del cuento. Buenos Aires: Guadalupe. 
Historia Universal de la Literatura. (1978). Barcelona: Sopena.

Huberman, M.; Thompson, C. L. y Weiland, S. (2000). Perspectivas de la carrera del profesor. En B. J. Biddle, T. L. Good y I. F. Goodson (Eds.). La enseñanza y los profesores, I. La profesión de enseñar. Barcelona: Paidós.

I Ching: el Libro de las mutaciones. Prólogo de C. G. Jung. Barcelona: Edhasa.

Kushner, E. (1989). Articulación histórica de la literatura. En Teoría literaria. Madrid: Siglo XXI.

Lao Tse (1984). Tao Te King. Barcelona: Orbis.

Lao Tse (2010). Tao Te Ching: Los libros del Tao (2⿳a ed.). Madrid: Trotta.

Lie Yukou (2008). Lie Zi. El libro de la perfecta vacuidad (4⿳亠丷a . ed.). Barcelona: Kairós.

Lyotard, J. (1989). La condición postmoderna. Barcelona: Cátedra.

Maspero, H. (2000). El taoísmo y las religiones chinas. Madrid: Trotta.

Montegut, E. (1982). Des fees et de leur littérature en France. París: Revuede Deux Mondes.

Radakhrisna y Rajú (2001). La naturaleza del hombre. México: Fondo de Cultura Económica.

Ricoeur, P. (1995). Tiempo y narración. Vol. I; Configuración del tiempo. Vol. II. Configuración del tiempo en el relato de ficción. Vol. III, El tiempo narrado. México: Siglo XXI.
Santamaría, A. y Ramírez, J. (2009). La narración: un modo de pensamiento. Sevilla: Universidad de Sevilla.

Tagore, R. (1994). El jardinero. Madrid: Edaf. Tucci, N. (2007). Confucio: el hombre superior y el arte de gobernar. Barcelona: Herder.

Vallejo, A. y Gómez, J. (2009). Crisis en la ciencia y la espiritual: ¿un fenómeno contemporáneo?: aproximaciones desde Husserl, Prigogine y desde la tradición taoísta. Hallazgos, 7(14), 39-58.

Vila, J. y Galvany, A. (2006). Yijing. El libro de los cambios. Con el comentario de Wang Bi. Girona: Atalanta.

Watts, A. (1994). El camino del Tao. Con la colaboración de Al Chung-liang Huang. Barcelona: Kairós

Watts, A. (2006). El camino del tao (9a․ ed.). Barcelona: Kairós.

Wellek, R. y Warren, A. (1974). Teoría literaria. Madrid: Gredos.

Wilhelm, R. (2007). I Ching. El Libro de las Mutaciones (32a. ed.). Barcelona: Edhasa.

Zhuang Zi (2005). Los capitulos interiores de Zhuang Zi. Madrid: Trotta.

Zhuang Zi (2007). El maestro Chuang Tsé. Barcelona: Kairós.

Zhuang Zi (2007). Zhuang Zi. Maestro Chuang Tsé (3a . ed.). Barcelona: Kairós. 